\title{
Laudatio ao Professor Eduardo García de Enterría y Martínez-Carande
}

\author{
Magnífica Reitora, Senhora Wrana Panizzi \\ Senhor Vice-Reitor, Prof. José Carlos Ferraz Henemman \\ Senhor decano da Faculdade de Direito, Prof. Sérgio Portos \\ Professor Eduardo García de Enterría y Martínez-Carande! \\ Minhas senhoras e meus senhores!
}

Reúne-se, neste momento, o Conselho Universitário da UNIVERSIDADE FEDERAL DO RIO GRANDE DO SUL, com O CORPO DE PROFESSORES DE SUA CENTENÁRIA FACULDADE DE DIREITO, a ptimeira faculdade de direito do Sul do Brasil, para, em sessão solene e histórica, efetivar o ato de concessão do título de DOUTOR HONORIS CAUSA -o mais alto galardão acadêmico- ao eminentíssimo Professor EDUARDO GARCIA DE ENTERRIA.

O PROFESSOR GARCIA DE ENTERRIA nasceu na região da Cantábria, noroeste da ESPANHA, em 1923. Fez a graduação e a pós-graduação nas Universidades de Barcelona e de Madrid. Completou a formação no Exterior, na Inglaterra (Londres) e na Alemanha (Tübingen).

Tornou-se catedrático de direito administrativo na Universidade de Valladolid, em 1957. Cinco anos depois, portanto em 1962, com apenas trinta e nove anos, conquistava a cátedra de direito administrativo na Universidade Complutense de Madrid. E no ano de 1970 alcançava, nessa Universidade, a direção do departamento de direito administrativo. 
Atuou na Revista de Administração Pública, desde sua fundação, em 1950, primeiro como Secretário Executivo e, depois, como Diretor. Participa da direção da Revista Espanhola de Direito Administrativo, desde sua fundação, em 1974. Vem integrando o conselho editorial ou científico de uma vintena de revistas especializadas, não só de seu País e de países iberoamericanos, mas também de periódicos da Inglaterra, França, Bélgica, Itália e Grécia.

O PROFESSOR GARCÍA DE ENTERRIA tem obrado com impressionante desenvoltura e liderança na área do direito europeu. Bastaria a lembrança dos oito anos de profícuo exercício do cargo de JUIZ DO TRIBUNAL EUROPEU DE DIREITOS HUMANOS, sediado em Estrasburgo, de abril de 1978 a fevereiro de 1986. Além dessa importantíssima função, ocupou a Presidência da FEDERAÇÃO INTERNACIONAL PARA O DIREITO EUROPEU -FIDE- de 1988 a 1990. E presidiu Congressos e Conferências de Direito Europeu do mais alto nível.

É fundador e atual presidente da ASSOCIAÇÃO ESPANHOLA PARA O ESTUDO DO DIREITO EUROPEU.

Receheu, em 1999, o PRÊMIO ALEXIS DE TOCQUEVILLE, do INSTITUTO EUROPEU DE ADMINISTR $\Lambda$ ÇÃO PÚBLICA de Maastricht, por unanimidade dos representantes dos então 15 Estados-Membros da Ủnião Européia.

Tem participado em seu PAÍS e na UNIÃO EUROPÉIA de COMISSÕES para elaboração de leis da maior relevância: Assim,

- na ESPANHA, entre muitas, PRESIDIU a comissão de especialistas que elaborou as bases dos PACTOS $\Lambda$ UTONÕMICOS dos últimos 12 ESTATUTOS de AUTONOMIA, em plena vigência;

- na UNIÃO EUROPÉIA, destaca-se a participação na elaboração dos trabalhos relativamente a projetos que vieram a influir:

- sobre Tratado de MAASTRICHT em vigor;

- sobre Carta Européia de Direitos Humanos;

- sobre as propostas referentes ao projeto de CONSTITUIÇÃO para a EUROPA. 
No âmbiro das instituições acadêmicas universitárias, além de uma série de prêmios de reconhecimento pelos seus méritos intelectuais e culturais, recebe, hoje, o seu DÉCIMO NONO título de DOUTOR HONORIS CAUSA. Esses títulos incluern a Universidade de Paris (Sorbonne), a Universidade de Bolonha, Universidades na Espanha, no México, na Argentina e em ourros países da Iberoamérica.

Eduardo García de Enterría

O QUE SIGNIFICA, esta noite, a atribuição a Vossa Excelência, do título HONORIS CAUSA?

De um ângulo, o mais aparenre, significa a prestação de uma homenagem merecidíssima, a um dos maiores juristas da humanidade, em nossa época. Este é o aspecto mais fácil de perceber a um primeiro exame.

Gostaria, porém, de descortinat um outro ângulo, ainda mais significativo.

Conforme a tradição acadêmica, o doutorado honoris causa importa a acolhida, em plano simbólico, do Professor homenageado, no corpo da Congregação Universitária Acadêmica que concede a titulação. Essa a razão do cortejo dos professores da Casa, que se organiza, nessa ocasião, em muitas das mais tradicionais Academias européias, para, em conjunto, receber o novo membro. Agora aqui também, Vossa Excelência passa a integrar, de forma muito especial, a Corporação dos Professores desta Instituição.

E para nós, professores da Faculdade de Direito desta Universidade, a honoris causa, a causa de honra de recebê-lo em nossa Congregação, como um dos nossos, em muito sobrepuja qualquer dignidade que, porventura, pudéssemos acrescentar a uma personalidade de tamanho valor intrínseco, acumulado em uma existência devotada toda ela ao ensino, à pesquisa e à literatura, no campo do direito. Portanto é profundo o agradecimento de nossa instituição por ter Vossa Excelência aceitado o título e se disposto a acolhê-lo em pessoa. 
Sinteticamente, condensaria em cinco pontos as grandes razões da nossa honra.

A PRIMEIRA, a vossa CULTURA JURÍDICA e a vossa CULTURA HUMANÍSTICA. Elas se encontram reconhecidas na Espanha e no Mundo. Não bastasse todo Vosso Currículo, um único fato tudo epitomiza. Vossa Excelência conquistou, de pleno direito, assento nas duas grandes Academias Reais de Espanha. Na Real Academia de Jurisprudência e Legislação, a cadeira - laurel máximo nas lerras jurídicas das EspanhasVos foi concedida em 1970. Já a Real Academia Espanhola Vos abriu suas portas em 1994, a mais excelsa honra ao mérito da literatura e da cultura no mundo hispânico, o que atesta o grande valor de vossos ensaios e escritos.

A SEGUNDA RAZÃO, o vosso incomparável e universal saber no direito administrativo. A vastíssima obra de Vossa Excelência, que alcança pelo menos vinte e oito hivros, todos reeditados, e um conjunto de várias centenas trabalhos, entre os quais recopilações legislativas, discursos, obras coletivas, participações em livros coletivos, contestações na Real Academia, Prólogos, Edições, Notas Críticas de Livros. Esta Casa, Professor GARCIA DE ENTERRIA, alegra-se em tê-lo entre os seus professores, também, porque tem uma rica tradição no direito administrativo. $O$ maior nome dentre os grandes juristas que aqui ensinaram, nos seus cem primeiros anos, certamente foi o do Professor RUI CIRNE LIMA, justamente o catedrático de Direito Administrativo, que ocupou, com o seu gênio, as décadas centrais do século passado. RUI fundou uma escola de pensamento, das mais importantes de nosso País, que é continuada pelo talento do Prof. ALMIRO DO COUTO e SILVA e pelos discípulos que este último tem formado ao latgo de mais de três décadas de ensino e de orientação.

A TERCEIRA RAZÃO de nossa honra reside na Vossa capacidade de liderança, que se alia com perfeição, à Vossa Cultura humanística e jurídica. Vossa Excelência é dotado do carisma do mestre, tão raro e tão valioso. Atestam as levas sem fim de discípulos que Vossa Excelência conquistou para o direito administrativo nas Espanhas, inclusive as das Américas. Este Carisma está em Vossa personalidade, cativante e encantadora, simples e acolhedora, capaz de incutir nos discípulos o amor pelo Direito. Qualidade ainda mais rara: Vosso Carisma penetra em vossa obra escrita e atinge as inteligências e os sentimentos dos leitores. Estes, mesmo os que nunca privaram de seu cativante convívio, tornam-se vossos discípulos, admiradores e seguidores das vossas lições.

A QUARTA RAZÃO DE NOSSA HONRA está ligada ao conteúdo de vossa imensa obra jurídica. Vossa Excelência, poderíamos dizer, sistematizou o direito 
administrativo espanhol, modelando suas vigas mestras, especialmente no Curso de Direito Administrativo, que já se encontra traduzido ao português. Ademais, Vossa Excelência pôsse à frente -como diz o título de seu livro já clássico- dA LUTA CONTRA AS IMUNIDADES DO PODER. Esse precioso trabalho abriu novos horizontes ao Estado de Diteito na Espanha dá época e em todo o mundo. Outra grande marca de Vossa obra jurídica foi ter ela influenciado o conteúdo, hem assim a interpretação, da Constituição espanhola de 1978, que este ano completa 25 anos. É notável Vosso trabalho "A Constituição como Norma e o Tribunal Constitucional", o primeiro estudo de peso sobre essa Instituição, que Vossa Excelência, como ninguém, concebe como um poder político independente de todos os outros, inclusive do Poder Judiciário, com a função de defender e de renovar o consenso que estabeleceu a Constituição da Espanha, democrática e estável, de nossos dias.

A ÚLTTMA E NÃO MENOS IMPORTANTE RAZÃO DE NOSSA HONRA está em que Vossa Excelência é o mestre dos mestres de todas as Espanhas, a cuja sombra cultural também o BRASIL foi formado e tornou-se de nação. $O$ direito, como a língua e como os costumes, é um pilar fundamental da identidade dos povos. Nenhuma sociedade pode enfrentar e resolver seus problemas de evolução e desenvolvimento, mesmo o econômico, divorciado de suas fontes culturais. Aí está um papel que Vossa Excelência tem cumprido nesta quadra da civilização brasileira e ibero-americana em geral.

Cumpre hoje superar, definitivamente, nossa crise de identidade cultural, agravada pelo impacto de outras matrizes que, repetidas vezes, têtn sido tomadas como modelo jurídico, sem análise mais cautelosa das conseqüências. Na orientação segura de vosso gênio jutídico poderemos encontrar as formas novas capazes de conduzir nossas nações a um desenvolvimento social, econômico e político, por meio de instituições jurídicas condizentes com as fontes que marcam a identidade de nossos povos. 